\title{
O processo de construção da identidade do adolescente com síndrome de Down no atendimento psicopedagógico.
}

\author{
Liz Leal Mota Capistrano ${ }^{1 *}$ \\ 1 Graduada em Pedagogia pela \\ Universidade do Estado da Bahia \\ (UNEB). Graduada em Matemática \\ pela Universidade do Estado da Bahia \\ (UNEB). Especialista em \\ Psicopedagogia Institucional e Clinica \\ pela Faculdade Católica de Ciências \\ Econômicas da Bahia (FACCEBA). \\ Professora do Atendimento \\ Educacional Especializado \\ /SEMEC/Serrinha \\ https://orcid.org/0000-0001-5206- \\ $\underline{2818}$
}

*Autor correspondente: alizleal@hotmail.com

\section{Resumo:}

Neste presente estudo, consideramos que o sujeito se constitui à medida que suas ações vão sendo expostos ou interagindo com o outro, através da internalização de papeis, definidos, inicialmente, pelas pessoas que são referências mais concretas do sujeito com Down. 0 objetivo foi refletir sobre o processo de formação e/ou construção da identidade dos adolescentes com Síndrome de Down durante os atendimentos psicopedagógicos no CAPENE Centro de Atendimento Pedagógico a Pessoas com Necessidades Educacionais Especiais do município de Serrinha-Bahia. Do ponto de vista metodológico a pesquisa fundamentou-se em uma investigação de cunho qualitativo, pautada na abordagem da investigação que adota as entrevistas narrativas como um importante instrumento de investigação, trazendo em seu interior depoimentos extraídos de entrevistas abertas e/ou semi-estruturadas. 0 estudo tem sua origem nos resultados obtidos em pesquisas realizadas com o grupo de adolescentes com Síndrome de Down, através de entrevistas narrativas. Os resultados revelaram a identidade negativa que o próprio sujeito tem em relação à deficiência. As análises realizadas procuram relacionar a identidade que esses sujeitos têm de si com a identidade transmitida pelo grupo social do qual eles fazem parte. Os resultados mostraram o discurso do grupo social nos dizeres dos sujeitos. Concluímos que para a transformação das identidades que os sujeitos com Síndrome de Down têm de si mesmo, precisamos de ações que incidam sobre aqueles que os rodeiam, ou seja, a família, os amigos, os colegas e o grupo social em geral.

Palavras-chave: Síndrome de Down. Identidades.

Deficiência. Entrevistas Narrativas.
REVISTA MACAMBIRA

Instituto Federal de Educação, Ciência e Tecnologia Baiano, campus Serrinha. Estrada Vicinal de Aparecida, s/n, Bairro Aparecida, Serrinha (Ba), CEP: 48700-000, sala 01, prédio acadêmico. 


\section{The process of constructing the identity of adolescents with Down syndrome in psychopedagogical care}

\author{
Liz Leal Mota Capistrano ${ }^{1^{*}}$ \\ 1Undergraduate in Pedagogy from \\ Universidade do Estado da Bahia \\ (UNEB). Undergraduate in \\ Mathematics from Universidade do \\ Estado da Bahia (UNEB). Specialist \\ in Institutional and Clinical \\ Psychopedagogy by Faculdade \\ Católica de Ciências Econômicas da \\ Bahia (FACCEBA). Specialized \\ Educational Service Teacher / \\ SEMEC / Serrinha \\ https://orcid.org/0000-0001-5206- \\ $\underline{2818}$
}

*Corresponding author: alizleal@hotmail.com

\begin{abstract}
:
In this study, we consider that the subject is formed as his actions are exposed or by the interaction with others, through the internalization of roles, defined, initially, by the ones who are concrete references of the person with Down Sundrome. Its purpose was to reflect on the process of identity formation and / or construction of adolescents with Down Syndrome during psychopedagogical consultations at CAPENE - Center for Pedagogical Assistance to People with Special Educational Needs in Serrinha - Bahia. From a methodological point of view, we conducted a qualitative investigation, based on the research approach that adopts narrative interviews as an important investigation tool, bringing testimonies extracted from open and / or semistructured interviews. The study is a result of the research carried out with the group of adolescents with Down Syndrome through narrative interviews. The results revealed a negative identity of these participants in relation to their disability. The analysis sought to relate the identity that these subjects have of themselves with the identity transmitted by the social group of which they are part of. The results showed the discourse of this social group in the subjects' speeches. This way, we conclude that we need to focus on the people around them, that is, their family, friends, colleagues and the social group in general in order to promote a change in the perception the people with Downs Syndrome have of their identities.
\end{abstract}

Keywords: Down syndrome. Identity. Deficiency.
MACAMBIRA JOURNAL

Federal Institute of Education, Science and Technology Baiano, campus Serrinha. Estrada Vicinal de Aparecida, s/n, Bairro Aparecida, Serrinha, Bahia, Brasil, CEP: 48700-000, sala 01, prédio acadêmico. 


\section{Introdução}

Este trabalho insere-se em um movimento de investigação que adota as entrevistas narrativas como perspectiva epistemológica e metodológica sobre a construção das identidades da pessoa com Síndrome Down. Relatamos o percurso da pesquisa; as reflexões teóricas que se constituíram a partir do diálogo com os autores que apresentamos ao longo do texto. Descrevo, também, as narrativas construídas por seis sujeitos com Síndrome de Down sobre suas vivências e experiências. Nos escritos, buscamos analisar algumas ideias sobre a constituição das identidades da pessoa com Síndrome de Down no atendimento psicopedagógico.

Os teóricos escolhidos para o estudo permitiram uma visão mais ampla do fenômeno em investigação. Com base nos estudos e nas leituras que realizamos foi possível construir uma reflexão mais aprofundada a respeito do cenário de construção das identidades da deficiência vivenciado pela pessoa com Síndrome de Down. Essas reflexões aguçaram ainda mais a indignação acerca do processo de invisibilidade desse sujeito em um contexto social que quase sempre lhe negou o direito de se expressar, de narrar sobre si, sobre suas significações acerca das experiências vividas na escola, na família e na sociedade, acerca do mundo experimentado. Dessa forma, o sujeito com Síndrome de Down (SD) foi historicamente aprisionado em rótulos, ideologicamente produzido pela sociedade e pela cultura.

Segundo Luciene Maria da Silva (2009), pessoas rotuladas passam a ser percebidas, a princípio, por suas diferenças que são negativadas, repercutindo fortemente no modo como elas irão se comportar, afinal, no processo de rotulação o indivíduo estigmatizado incorpora determinadas representações e passa a se identificar com uma tipificação que o nega como indivíduo.

Neste contexto, a invisibilidade da pessoa com deficiência nas relações pessoais e sociais, caracteriza-se pela sua ausência física real, a qual impede a construção de laços e interações responsáveis pela inserção de qualquer indivíduo em um grupo.

Glat (2004) fala da importância de entrevistar/ouvir pessoas com deficiência intelectual, uma vez que se deixa de focar na limitação para compartilhar experiências de sua vida. Dessa forma, buscamos compreender o processo identitário a partir da visão dos próprios adolescentes com SD, conforme suas vivências no grupo de atendimento psicopedagógico e com isso fazer escutas respeitosas e oportunizamos espaços para que falem a esses sujeitos.

A relevância desse estudo deve-se, portanto, ao fato da temática ser pouco estudada na área da educação, sobretudo na educação especial e, ainda, por envolver questões sobre educação especial, identidade e adolescente que o torna um estudo singular e original. Pretende-se, portanto, contribuir com esse debate e propor novas possibilidades de pesquisa e compreensão da realidade, através da investigação qualitativa que priorizou como caminhos metodológicos as entrevistas narrativas.

Nesta investigação, foram selecionadas seis pessoas com SD (três meninos e três meninas), com idade entre 12 anos a 17 anos que frequentam o atendimento psicopedagógico no CAPENE- Centro de 
Apoio Pedagógico a Pessoa com Necessidades Educacionais Especiais. O CAPENE está localizado na sede do município baiano de Serrinha, na região do semiárido do nordeste do Brasil. Atende a um grande número de estudantes de várias localidades do município e um pequeno número de municípios vizinhos. Conta com uma equipe multiprofissional especializada e com diversos espaços para a realização de atividades, que acontecem semanalmente no contraturno da escola regular.

Tendo em vista atender aos objetivos desse trabalho, fundamentamos com alguns suportes teóricos imprescindíveis na discussão do objeto de investigação, aqui, apresentados: VYGOTSKY (2011), GLAT (1989), CAMARGO (2000), GUIMARÃES (2003), ERIKSON (1972), FREITAS (2003), KASSAR (2000), SCHWARTZMAN (1999), JANNUZI (1992), PIMENTEL (20007), GOFFMAN (1988), entre outros.

\section{Um olhar sobre a pessoa com síndrome de Down}

\section{A pessoa com síndrome de Down}

Essa pesquisa não tem o intuito de enfatizar as características físicas, as possíveis limitações, nem a configuração genética da pessoa com SD. No entanto, antes de discutir sobre a construção de sua identidade, um dos focos principais dessa pesquisa, consideramos relevante trazer, de forma breve, algumas informações e reflexões sobre os aspectos físicos e cognitivos apresentados pelas pessoas com SD.

A SD é uma disfunção genética, um desequilíbrio na constituição cromossômica causado pela presença de um cromossomo extra no par 21, por isso é conhecida também como trissomia 21 ou trissomia simples. Frequentemente essa trissomia do cromossomo 21 resulta em características físicas, sensoriais e cognitivas marcantes, incluindo o fenótipo clássico, a deficiência intelectual, com consequente atraso do desenvolvimento, sendo muito visível no campo linguístico, com alterações motoras e orgânicas que comprometem diretamente o desenvolvimento dessa população (SCHWARTZMAN, 1999).

Dentre as características fenotípicas da síndrome destaca-se o tônus muscular baixo, denominado de hipotonia que, em geral, afeta todos os músculos do corpo o que pode comprometer os movimentos, a força e o desenvolvimento de algumas habilidades. Outras características fenotípicas envolvem: aparência arredondada da cabeça, pescoço curto, os olhos podem parecer inclinados para cima (fissuras palpebrais oblíquas), também podem ter pequenas dobras de pele - chamadas de pregas epicânticas - nos seus cantos internos, boca pequena - podendo projetar um pouco a língua, as mãos e os pés podem ser menores e seus dedos podem ser mais curtos - única prega na palma da mão e baixa estatura. É importante destacar também que, apesar de possuírem alterações fenotípicas semelhantes, as pessoas com SD 
diferem entre si dos aspectos gerais do desenvolvimento como: linguagem, motricidade, socialização e habilidades da vida diária (PIMENTEL, 2007).

Essa síndrome também pode ser caracterizada por uma translação ou um mosaico. No caso da translação, todo, ou uma porção, do cromossomo extra encontra-se ligado ao cromossomo 14. Este processo difere daquele que ocorre na trissomia simples do 21 , uma vez que, a trissomia simples, é resultado de uma alteração cromossômica numérica, devido a uma não disjunção na formação da meiose. A ocorrência deste tipo de anomalia é de 3\% a 4\% das pessoas com Síndrome de Down. Esse é o único caso em que a SD pode ser hereditária. (SHWARTZMAN, 1999).

Todos esses avanços nas pesquisas genéticas contribuíram para uma maior compreensão das questões relacionadas à SD, melhorando assim a vida dessas pessoas. Seu tempo de vida aumentou a educação e o cuidado das pessoas com essa síndrome também melhoraram significativamente. Durante muitos anos, considerava-se que a SD era uma doença e que era necessário um tratamento medicamentoso, o que não é verdade. E o pior, considerava-se que as pessoas com SD não tinham potencial, não eram capazes de aprender, de se relacionar, de exercer uma profissão. Com essa visão preconceituosa da sociedade a respeito de suas capacidades, negavam-lhes as oportunidades necessárias para o exercício de sua cidadania.

\section{O processo de construção da identidade da pessoa com síndrome de Down}

A discussão do pensamento acerca da composição identitária da pessoa com SD é inscrita na perspectiva Socio-Histórico-Cultural, principalmente no pensamento de Vygotsky (2001) argumentando que os seres humanos constituem-se socialmente através das interações vivenciadas em seu meio social. Ao vivenciar as experiências socialmente, o indivíduo apropria-se dessas experiências, o que contribui para a construção da identidade, para sua subjetividade, pois, “[...] a subjetividade não existe a priori, mas concretiza-se no processo de introduzir, evidenciando que o desenvolvimento acontece de modo partilhado.” (KASSAR, 2000, p.44).

Qualquer sujeito traz consigo uma herança cultural significativa, repleta de experiências e aprendizados, valores e características de uma sociedade que está sempre em movimento. Esse sujeito acompanha essa dinâmica, demonstrando sua incompletude, sendo a presença do outro a condição imprescindível na construção da identidade e “[...] como as relações são sucessivas e infinitas, não se tem nunca um sujeito absoluto" (CAMARGO, 2000, p. 27). Nesse contexto, pode-se afirmar que as relações que vão sendo estabelecidas entre os sujeitos acabam produzindo mudanças em cada indivíduo, o que pode favorecer o processo de consciência de si e a constituição de sua própria identidade, portanto, "Essa estrutura humana complexa é o produto de um processo de desenvolvimento profundamente enraizado nas ligações entre história e história social [...].” (VYGOTSKY, 2001, p.33). 
Nessa lógica, é possível dizer que a construção da identidade da pessoa com SD começa no momento do nascimento e vai se constituindo por meio da própria experiência e da imagem de si percebida por si mesmo e pelos outros. Essa relação entre as construções culturais que acontecem no social e no desenvolvimento humano repercutem na constituição do sujeito, na produção de práticas e discursos cotidianos. Por isso, a pessoa com SD, ao narrar sobre si, sobre suas vivências na escola, na família e na sociedade traz consigo a marca do outro do social. Assim, “[...] o modo como as pessoas se vêem [...] ou significam sua existência também se dá circunscrito socialmente, na tensão entre diferentes vozes, que aos poucos vai encontrado ou não repercussão no indivíduo [...]” (KASSAR, 2000, p. 44).

Segundo Vygotsky (1991), a constituição do sujeito não é determinada por fatores biológicos, mas, sobretudo, por fatores históricos e sociais. Nessa mesma linha Pimentel (2008, p. 13) afirma que “[...] o homem enquanto sujeito multideterminado não está limitado às determinações biológicas de sua espécie, mas é construído enquanto ser único e distinto, a partir das interações travadas no interior de sua cultura $[\ldots] "$.

Ao desconsiderar a pessoa com SD como um sujeito único que faz parte de uma sociedade plural, impede-se de descobrir suas potencialidades, de perceber a essência de si mesmo, contribuindo para a construção de subjetividades e identidades estereotipadas, fixadas em rótulos, podendo formar o que Goffman chama de "identidades deterioradas", carregadas de estigmas.

Ao discutir a questão do estigma, Goffman (1988) conta que o termo foi criado pelos gregos para se referirem aos sinais corporais utilizados para marcar o que era extravagante ou mau relativamente ao estado moral de quem os possuía. Esse sinal era feito com cortes ou fogo e caracterizaria, “[...] uma pessoa marcada, ritualmente poluída, que deveria ser evitada, especialmente em lugares públicos.”. Neste ponto de vista, o estigma seria a situação na qual o indivíduo está “[...] inabilitado para a aceitação social plena." e ainda evidenciaria um atributo depreciativo, referindo-se a uma "[...] pessoa estragada ou diminuída [...]" (GOFFMAN, 1988, p.12).

De acordo com o autor, o indivíduo estigmatizado seria alguém não completamente humano, que vivencia diversas formas de discriminação e que poderia, por assim dizer, ter suas chances de vida reduzidas. A partir desse argumento, constitui o conceito de "desacreditado" e "desacreditável", sendo que, o primeiro termo indica que o atributo que caracteriza o sujeito está explícito e, o segundo, indica algo implícito.

Conforme Goffman (1988), a identidade se divide em "pessoal" e "social". A “[...] identidade pessoal” é formada por “[...] marcas positivas ou apoio de identidade e a combinação única de itens da história de vida que são incorporados ao indivíduo com o auxílio desses apoios para a sua identidade [...]”. Desta forma, o indivíduo é singular, diferente dos demais. Já a “identidade social” está atrelada ao tipo de papel que o indivíduo é capaz de sustentar, sendo formada pelo total de atributos e categorias que as pessoas possuem. Essa identidade, por sua vez, se subdivide em "identidade social virtual", que diz 
respeito aquela dada pelo outro e a "identidade social real" que se refere às categorias e atributos que o sujeito, realmente possui (GOFFMAN, 1988).

Essas questões equivocadas sobre o assunto acabam fomentando uma série de preconceitos que gera, ainda hoje, a exclusão desses sujeitos. Segundo Pimentel (2007), “[...] as trocas com o contexto social estão fortemente relacionadas com a forma como a sociedade lida com a diferença [...]". No caso da pessoa com SD, essa diferença é visivelmente perceptível pela aparência típica, peculiar à sua condição e, por essa razão, constitui-se em um fator estigmatizante da mesma. O que dificulta, muitas vezes, o convívio social sendo, em alguns casos, tratado com atitudes de indiferença e desinteresse, gerando a exclusão.

Para Glat (1989), os sujeitos vão configurando as suas respectivas identidades a partir das percepções e representações dos que estão a sua volta. Nesse sentido, conclui-se que a identidade que a pessoa com deficiência constrói de si mesma reflete a visão de seus parceiros sociais.

Lima, Maia e Distler (1999) acrescentam a essa ideia, o fato de que sendo a família o núcleo social básico, as relações aí estabelecidas irão depender das relações interpessoais de seus integrantes. Assim, as experiências da vida familiar podem auxiliar ou dificultar o processo de desenvolvimento de seus membros. Em outras palavras, o que a pessoa "é" depende de como "são" estabelecidas às relações familiares.

Para Erikson (1972), construir uma identidade implica em definir quem a pessoa "é", quais são seus valores e quais as direções que deseja seguir pela vida. Para ele, o termo identidades pode ser entendido como a concepção de si mesmo, composta de valores, crenças e metas com as quais o indivíduo estar solidamente comprometido. O autor afirma que é obrigação das gerações mais velhas transmitirem valores sólidos, sobre os quais os mais novos irão construir sua identidade.

Como percebemos em todos os estudos citados, a interpretação que o grupo faz do sujeito é muito importante para a leitura que esse fará de si mesmo e para sua constituição. Se a sociedade tiver concepções negativas das pessoas com deficiência- ou não conseguir interpretar suas ações como significativas -, esses sujeitos vão se constituir a partir dessa imagem e suas ações retratarão essa visão social.

\section{Percursos metodológicos}

O processo de pesquisa sempre esteve presente no estudo das ciências naturais e sociais. $\mathrm{Na}$ atualidade, a pesquisa permanece sendo valorizada como a forma mais adequada para se conhecer e compreender a realidade. Segundo Barros e Lehfeld (1990, 1990, p.24) “[...] pesquisa é a exploração, é a aquisição, é o procedimento sistemático e intensivo que tem por objetivo descobrir, explicar e compreender os fatos que estão inseridos ou que compõem uma determinada realidade [...].”. 
Nos estudos desenvolvidos no sentido sócio-histórico, conforme apontado por Freitas (2003) procura-se no processo de pesquisa, a oportunidade de reflexão e ressignificação do pesquisador e do pesquisado, uma vez que o pesquisador é considerado parte integrante da pesquisa, pois a sua compreensão dos fenômenos se constrói a partir do lugar que ocupa e das relações que estabelecem com os sujeitos os quais pesquisa. Assim, os dados obtidos durante a situação de interação entre os sujeitos permitirão, também, a compreensão do contexto social no qual eles emergem, permitindo que se estabeleçam relações entre eventos investigados em uma integração do individual com o social.

Sendo assim, adotamos uma investigação pautada na pesquisa qualitativa fortemente desenvolvida pelas pesquisas no campo das ciências humanas que busca, a partir da utilização de alguns procedimentos, superar os limites meramente quantitativos e alargar uma discussão de fenômenos sociais que não são facilmente mensuráveis como aponta o método positivista, merecendo, desse modo, um olhar mais criterioso e reflexivo no tratamento das questões pesquisadas.

Uma investigação que compreende a informação e o sujeito da pesquisa como prioridade, exige uma aproximação do pesquisador com os pesquisados. É preciso, portanto, estabelecer contato, interações, para que a partir daí, se construa uma relação de respeito e confiança. Com esse objetivo buscamos compreender a construção das identidades dos adolescentes com SD, que frequentam as sessões psicopedagógicas.

A pesquisa qualitativa se preocupa com os sujeitos e seus espaços em suas complexidades, de modo que o pesquisador não impõe limites e/ou controle, antes, busca com seriedade retratar a perspectiva dos participantes, ou seja, o sentido que eles dão às coisas e à vida. Desse modo, são percebidos como as peças mais importantes no processo, afinal, “A centralidade do sujeito no processo de investigação [...] sublinha a importância das relações entre subjetividade e narrativa como princípios que concedem ao sujeito o papel de ator e autor de sua própria história" (SOUZA, 2006, p.36).

Dessa maneira, a partir da necessidade de um olhar mais particular, firmamos o caminho da metodologia das entrevistas narrativas que se utilizam as trajetórias pessoais no âmbito das relações humanas, buscando conhecer as informações contidas na vida pessoal, fornecendo uma riqueza de detalhes sobre o que se pretende investigar. Nesse sentido, constituem-se como um importante instrumento de investigação distinguindo-se de outros métodos, sobretudo os quantitativos, pois trazem em seu bojo depoimentos extraídos de entrevistas abertas e/ou semi-estruturadas.

Esse estudo foi realizado com a atuação de seis sujeitos com SD: Lucas, Paulo, João, Laura, Joana e Maria. Os adolescentes tinham entre 12 e 17 anos de idade quando os encontros foram realizados, eles (elas) participavam semanalmente dos atendimentos psicopedagógicos. Nesse trabalho, os adolescentes foram identificados por nomes fictícios, com o objetivo de preservar a real identidade dos sujeitos. 
Procuramos examinar como se desenvolveram as argumentações de cada participante ao longo dos diálogos ocorridos nos encontros. Tentamos determinar de que modo os vários discursos, dos diferentes membros da reunião, refletiram suas posições (lugares) sociais influenciou os sentidos construídos.

No presente estudo, utilizamos entrevistas semi-estruturadas por essas permitirem um olhar e uma escuta mais direta e precisa da trajetória de escolarização, da família de indivíduos com SD. Foi empregado para buscar informações um roteiro prévio de questões abertas a serem respondidas oralmente pelos entrevistados. Nesse tipo de entrevista, a intenção em ouvir o sujeito, o pesquisador seleciona e restringe os temas que serão abordados. O importante é que nessas entrevistas ao invés de apenas responder as perguntas determinadas e estabelecidas pelo pesquisador, os sujeitos são livres para contar sobre aquilo que consideram relevante em sua experiência, a forma como vivenciaram os fatos narrados e como esses interferem no presente (GLAT, 1989).

\section{Análise e interpretação de dados}

Em concordância com o descrito anteriormente, o presente estudo procurou refletir sobre a formação da identidade de adolescentes com SD que participam de atendimento psicopedagógico, realizado em grupo.

Posteriormente a leitura e análise dos dados colhidos na entrevista, foram levantados alguns temas, resultantes dos momentos da reunião nos quais ficaram mais determinados os sentimentos relacionados à imagem que os sujeitos fazem de si mesmos. Destaca-se, que nem sempre o discurso dos adolescentes permitia uma identificação explícita da imagem que ele estava fazendo de si, naquele momento. Mas, o contexto no qual o discurso emergia e o olhar atento para os detalhes da interação que acontecia no grupo possibilitaram que se compreendesse e se relacionasse eventos singulares com o discurso circulante em nossa cultura, permitindo, dessa forma, direcionarmos nossa reflexão para o foco proposto nesse estudo.

Em seguida, apresentamos um dos fatos que ocorreu em momentos distintos de atendimento no grupo terapêutico psicopedagógico, os quais permitem refletir sobre a imagem que esses sujeitos fazem de si.

\section{SITUAÇÃO 1:}

Os sujeitos discutiam sobre a preferência musical de cada um. A discussão teve início após a psicopedagoga, P, questionar o gosto musical de Lucas. Participavam da reunião, P (psicopedagoga) e os adolescentes: Paulo (15 anos), Maria (12 anos), Laura (16 anos), Joana (16 anos), João (16 anos) e Lucas (17 anos).

Lucas - Gosto de Rap.

P - Você gosta de Rap? Verdade?

Lucas - (faz sinal positivo com a cabeça).

Laura - Eu também gosto de Rap.

P - Que grupo você gosta? (referindo-se, ainda, à Lucas). 
Lucas - Um monte.

P - Um Monte. Meu irmão também gosta de rap, sabia?

Maria - Eu gosto só hino.

P - Você gosta de hino?

Maria - Gosto, você não gosta?

P - Eu gosto, eu acho bonito. Você não acha bonito o que eles falam no hino? (referindo-se à Maria).

Laura - Eu gosto. A Damara, a minha colega, gosta do hino.

P - Verdade!? Como é que é o hino?

Laura- (levanta os ombros, referindo não saber).

P- Não lembra? Que hino você gosta, Maria?

Laura - (fala ininteligível, ao mesmo tempo em que a terapeuta faz a pergunta para Maria).

Maria - Cassiane.

P - Quê?

Maira - Cassiane.

P - Cassiane? É uma cantora?

Maria- Ela é.

$\mathrm{P}$ - Como que chama, Maria?

Maria - Cassiane.

P - Cassiane?

Maria - (faz gesto afirmativo com a cabeça).

$\mathrm{P}$ - E você, Joana? Você gosta de algum cantor, alguma música?

Joana - (faz gesto afirmativo com a cabeça).

$\mathrm{P}$ - De quem você gosta?

Joana - Da Xuxa.

$\mathrm{P}$ - De quê?

Joana- Da Xuxa.

$\mathrm{P}$ - Da Xuxa? Ah, que legal, quem mais?

Joana - (Não responde).

$\mathrm{P}$ - E você, João, você ouve música?

João - Não.

\section{SITUAÇÃO 2:}

Nesse fato, participavam da reunião, P (psicopedagoga) e os adolescentes: Paulo (15 anos), Maria (12 anos), Laura (16 anos), Joana (16 anos), João (16 anos) e Lucas (17 anos). O grupo está conversando sobre suas preferências. A discussão tem início após a psicopedagoga perguntar a um dos sujeitos sobre a sua preferência.

P - Que tipo de música você gosta?

João - Da Xuxa (sorrindo).

P - Da Xuxa, ele gosta da música da Xuxa (falando com Lucas).

$\mathrm{P}$ - E você, Lúcia?

Maria- Eu gosto... (inaudível).

P - Rock? E você, Alex?

Joana - Lucas.

$\mathrm{P}$ - Daniel! Daniel é bom!

João - (dá risada e bate na mesa).

P - E você, Paulo? Que música você gosta?

Paulo - (estica uma das mãos, e com o dedo indicador da outra mão faz um círculo em sua mão esticada).

Laura - Ele que rock.

$\mathrm{P}$ - O que é isso?

Paulo - (continua fazendo o movimento com as mãos).

P - É o disco?

Paulo - (com uma mão faz como se estivesse pegando algo, como uma pinça).

P - Você comprou também? 
(Laura) (faz gesto afirmativo com a cabeça).

$\mathrm{P}$ - Eu vi o seu CD. Como que chamava mesmo? Você mostrou o CD que você comprou, é de uma dupla sertaneja!

Paulo - (verbaliza e aponta para cima)

P - É de uma dupla sertaneja, né!

$\mathrm{P}$ - E você Laura, que música você gosta?

Laura - Zezé di Camargo e Luciano (dando risada e deitando a cabeça sobre a mesa)

Lucas - começa a música e Laura, logo em seguida, acompanha-o. "Minhoca, minhoca, me dá uma beijoca, não dô..."

P - Mas essa música é de criança, canta outra que você gosta.

Laura - Eu gosto di... (fala inaudível).

$\mathrm{P}$ - Ah? Você gosta de qual?

Laura- Esse aí.

$\mathrm{P}$ - Essa que a gente tava cantando?

Laura- Não.

P - Então canta!

Lucas - "Minhoca, minhoca..."

Nestes dois episódios, podemos observar a postura infantil que alguns sujeitos assumem ao revelarem as suas preferências musicais. Joana, no primeiro episódio, diz que gosta da Xuxa. João, então com 16 anos de idade, também afirma, no segundo episódio, gostar da Xuxa. Laura e Lucas, ao serem questionados sobre as suas preferências musicais, começam a cantar uma música típica de criança: "Minhoca, minhoca...". Os sujeitos revelam ora ocupar o lugar de jovens, quando alguns manifestam gostar de músicas ouvidas e apreciadas por jovens de seus grupos sociais (Rap e Hinos religiosos), ora assumem a posição de crianças, quando outros indicam preferência por um estilo de música bastante infantil, que, provavelmente, não seria um estilo apreciado pelos outros jovens de mesma idade. Fica explícita, assim, a imagem não clara que os jovens fazem de si. Entretanto, esta imagem não é formada independentemente do grupo social, mas construída socialmente por este grupo.

Conforme apontado por Góes (2004), aquilo que os sujeitos revelam em seus discursos é o resultado do modo como eles assimilam em suas próprias falas os dizeres das diferentes vozes do grupo social. Os enunciados produzidos pelo grupo são incorporados e vão compor a imagem que fazem de si. Isto significa dizer que a constituição do sujeito se dá pela linguagem, através de um processo essencialmente dialógico, que procede das e ocorre nas interações sociais. Nas palavras de Bakhtin:

O sujeito é constituído por diversas vozes - polifonia. Quando se expressa, usa uma linguagem que não é só dele, é também de outros. O fato de ser constituído por muitas vozes concorre para a heterogeneidade do sujeito. Essa heterogeneidade provém da constituição do "eu" e do "outro", o outro que é constituído, também, por muitas vozes, numa cadeia infinita de "outros". (BAKHTIN, 1997, p. 314).

Um terceiro episódio torna mais claro a relação entre as vozes do grupo e os dizeres do sujeito deficiente. Nele vemos as duas terapeutas, que ali representam o grupo social, revelando uma expectativa bastante infantil em relação ao sujeito deficiente.

SITUAÇÃO 3: 
Nesta situação, participavam da reunião, P (psicopedagoga) e os adolescentes: Paulo (15 anos), Maria (12 anos), Laura (16 anos), Joana (16 anos), João (16 anos) e Lucas (17 anos). O grupo está conversando sobre suas preferências. A discussão tem início após a psicopedagoga perguntar a um dos sujeitos sobre a sua preferência.

P - O que você mais gosta de fazer, Laura?

Laura - Tudo

P - Tudo. Mas o que você mais gosta de brincar, de fazer?

Laura - Brincar, de assistir televisão e várias coisas!

$\mathrm{P}$ - Ah, e você, Lucas?

Lucas - Fala ininteligível.

$\mathrm{P}$ - Nossa, é legal, mas eu não sei jogar muito bem e o que mais?

Lucas - Só.

$\mathrm{P}$ - E você, João, o que mais gosta de fazer?

João - (está concentrado, folheando uma revista, por isso nada responde).

$\mathrm{P}$ - Oh, agora a gente tá conversando.

João - (permanece olhando para a revista).

$\mathrm{P}$ - Você gosta de recortar?

João - (faz gesto afirmativo com a cabeça).

$\mathrm{P}$ - Que mais?

João - (faz gesto negativo com a cabeça).

P - Só? E você, Paulo?

Paulo - (não responde)

P - Você gosta de andar a cavalo, né?

Paulo - (faz gesto afirmativo com a cabeça).

P - Que mais?

Laura - Eu também gosto de andar de cavalo.

$\mathrm{P}$ - Oi?

Laura - Eu também gosto de andar de cavalo.

P - Você também gosta? E vocês também gostam? (referindo-se a Lucas e João).

Laura - Ele faz assim: "Segura peão!"

P - É assim que faz, Paulo?

Paulo - (faz gesto afirmativo com a cabeça).

$\mathrm{Na}$ tentativa de obter uma resposta mais específica, a piscopedagoga tenta explicar melhor a sua pergunta e acaba revelando uma expectativa infantil em relação ao sujeito com SD. Observamos a piscopedagoga perguntando a uma jovem de 17 anos: "Mas o que você mais gosta de brincar, de fazer?" Este pequeno detalhe não só revela a imagem que a terapeuta tem do sujeito, mas colabora para incentivar a conversa nessa direção.

De acordo com Kassar (2000), a constituição da subjetividade do indivíduo é marcada pelas condições materiais e ideológicas nas quais o indivíduo se insere. A capacidade de significar (dar sentido, interpretar e fazer-se entender) de cada indivíduo passa a existir pelos significados atribuídos pelos outros às suas ações. O "significar do outro" está na gênese do comportamento "significativo" do "eu", na gênese do pensamento de cada indivíduo, que vai constituindo-se inserido em uma constituição/organização do pensamento. Observamos outras possibilidades como o fortalecimento dos laços familiares, a existência de outros amigos que não são Down, a questão da idade cronológica, essas afirmações contribuem para a construção da identidade. 


\section{Considerações finais}

Esse trabalho analisou e buscou dar visibilidade ao processo de construção da identidade através das narrativas de seis adolescentes com SD que frequentam um grupo de terapia psicopedagógica. Os conceitos e valores, o modo como as pessoas significam sua existência também acontece socialmente, na tensão entre diferentes vozes, que aos poucos vão encontrando ou não reflexão no indivíduo.

No discurso dos adolescentes que participaram desse estudo, pudemos observar uma imagem de si mesmo significativa dos valores e expressões atribuídos pela sociedade a sujeitos com SD. A imagem infantil que os adolescentes têm de si mesmos reflete o discurso do grupo social que está a sua volta. A própria psicopedagoga, quando pergunta ao adolescente do que ele gosta de fazer, deixa escapar em seu discurso a visão infantil que tem do mesmo.

A transformação ou não da imagem que os sujeitos com SD fazem de si mesmos permite-nos avaliar o quanto as terapias psicopedagógicas podem colaborar ou não para o desenvolvimento da linguagem e para a constituição de cidadãos.

Porém compreende-se que, as características físicas, comportamentais ou emocionais não são os únicos aspectos que determina a não aceitação por parte dos pares e que torna João, Paulo, Lucas, Maria, Joana e Laura, mais expostas às ações de exclusão social. Mas, principalmente a característica de deficiência intelectual que é associada à síndrome. Ficou evidente que essa condição de desvantagem intelectual é uma das principais causas dos estigmas de inferioridade, de incapacidade atribuída à pessoa com SD e dos principais motivos de discriminação e rejeição enfrentados por esses sujeitos.

Essas experiências de exclusão, de solidão, comprometem o processo de formação de sua identidade, tendo sua autoestima rebaixada, causando medo e ansiedade, sentindo-se inseguras e desprotegidas. É importante destacar que o estudo aponta a construção da identidade como um processo social, histórico e cultural, que se constituem nas relações entre os sujeitos. Sendo que essas relações podem interferir de maneira negativa ou positiva no processo identitário das pessoas com Síndrome de Down.

Percebe-se que, as identidades levam consigo a concepção de sujeito ativo. No entanto, nem todas as pessoas com SD chegam a serem sujeitos ativos de sua própria vida. E, possivelmente, essa dificuldade não se deve a deficiência, mas a automatização e a exigência a que os submetemos que acaba sufocando seu desejo e pode levá-los a se desconectar de sua vida afetiva. Frequentemente dizemos o que eles têm que fazer e como fazer. Uma pessoa com deficiência, mesmo que tenha recursos suficientes não é concebida como capaz de saber de si mesma - permanecerá alienada no outro e dificilmente poderá se diferenciar de seus pais ou se tornar sujeito com desejo próprio.

Nesse ponto de vista, é possível falar que a construção da identidade da pessoa com SD vai se constituindo pelas experiências vivenciadas por meio de si mesmo e pelos outros. Assim, conforme a análise dos depoimentos dos entrevistados ficou visível que quando a identidade da pessoa com SD é 
construída pelo outro com depreciação, preconceitos e infantilidade, gera um conflito interior entre o que os outros pensam dela e o que ela mesma acredita ser. Uma vez que João, Paulo, Lucas, Maria, Joana e Laura têm se constituído enquanto sujeitos em um contexto social que ainda enxerga a pessoa com SD pelo ângulo da limitação e das impossibilidades, esse contexto, revela também que o olhar do outro é na maioria das vezes um olhar que discrimina, desconfia de suas capacidades.

Para conseguirmos obter as mudanças necessárias e transformar a imagem que os sujeitos com SD têm de si mesmos, precisamos de ações que incidam sobre aqueles que os rodeiam, ou seja, a família, os amigos, os colegas e o grupo social em geral. É urgente que tais ações sejam iniciadas e que considerem a natureza do processo, muitas vezes, lento e difícil para conquistar mudanças nos valores e práticas social.

Necessitamos levar tais reflexões para os cursos de formação dos profissionais que atuarão junto a esses sujeitos e suas famílias. Através da mudança nos olhares de educadores e terapeutas podemos transformar, ainda que lentamente, a imagem que o grupo social tem dos sujeitos com SD e, assim, garantir os direitos desses em nossa sociedade.

\section{Referências}

ARFUCH. L. O espaço biográfico: Dilemas da subjetividade contemporânea. EDUERJ, Rio de janeiro, 2010.

BARROS, Aidil de Jesus Paes de. Projeto de pesquisa: propostas metodológicas. Aidil de Jesus Paes de Barros, Neide Aparecida de Souza Lehfeld. Rio de Janeiro: Vozes, 1990.

BAKHTIN, M. Marxismo e Filosofia da Linguagem. 4. ed. São Paulo: Hucitec, 1988.

BAKHTIN, M. Estética da criação verbal. São Paulo: Martins Fontes, 1997.

BERTAUX, Daniel. Narrativas de vida: A pesquisa e seus métodos. Paulus, São Paulo, 2010.

BENVENISTE, Emile. História/Discurso (Notas sobre dois voyeurismos). IN: Xavier, Ismael (Org.). A experiência no cinema: antologia Rio de Janeiro: Edições Graal: Embrafilme, 1983.

BOURDIEU, Pierre e PASSERON, Jean-Claude. A Reprodução: Elementos para uma Teoria do Sistema de ensino. Rio de Janeiro: Livraria Francisco Alves, 1989.

CAMARGO, Evani Andreatta Amaral. Concepções de deficiência mental por pais e profissionais e a constituição da subjetividade da pessoa deficiente. Campinas, SP, s.n, 2000. Tese doutorado.

CARNEIRO, Maria Silva Cardoso. Deficiência mental como produção social: uma discussão a partir de histórias de vida de adultos com síndrome de Down. Tese de doutorado. Porto Alegre, 2007.

CARNEIRO, Maria Sylvia Cardoso. O uso de métodos narrativos na pesquisa obre deficiência mental: histórias de vida de adultos com síndrome de Down (CED/UFSC. www.scielo.br/scielo.php).

CASARIN, S. Os vínculos familiares e a identidade da pessoa com síndrome de Down. São Paulo: Pontifícia Universidade Católica de São Paulo, (Dissertação de Mestrado). (2001). 
DINIZ, Debora. O que é deficiência. São Paulo: Brasiliense, 2007.

ERIKSON, E. H. Identidade, juventude e crise. Rio de Janeiro: Zahar, 1972.

FREITAS, M. T. de A. A perspectiva sócio-histórica: uma visão humana da construção do conhecimento. In: FREITAS, M. T. A. et al. Ciências Humanas e Pesquisa: leituras de Mikhail Bakhtin. São Paulo: Cortez, 2003. p. 26-38.

FERREIRA, M. E. C.; GUIMARÃES, M. Educação Inclusiva. Rio de Janeiro: DP\&A, 2003.

FOUCAULT, Michel. Vigiar e punir: nascimento da prisão. 29 ed. Petrópolis: Vozes, 2004.

GHEDIN, Evandro; FRANCO; Maria Amélia Santoro. Questões de método na construção da pesquisa em educação. São Paulo, Cortez, 2008.

GLAT, R. Somos Iguais a Vocês: Depoimentos de Mulheres com Deficiência Mental. Rio de Janeiro: Editora Agir, 1989.

GLAT, R., FREITAS, R. C. Sexualidade e Deficiência Mental: Pesquisando, Debatendo e Refletindo sobre o Tema. Rio de Janeiro: Editora Sete Letras, 1996. MULLER, T. M. e GLAT, Rua Uma Professora Muito Especial. Rio de Janeiro: Editora Sete Letras, 1999.

GLAT, R., Rosana. et al. O método de história de vida na pesquisa em educação especial. Revista Bras. Marília, maio/agosto, 2004, v.10, nº 2, p.235-250.

GOFFMAN, Erving. Estigma: notas sobre a manipulação da identidade deteriorada. Rio de Janeiro RJ: Livros Técnicos e Científicos Editora S.A., 1988.

GOES, M. C. R. de. Desafios da inclusão de alunos especiais: a escolarização do aprendiz e sua constituição como pessoa. In: GÓES, M. C. R.; LAPLANE, A. L. F. (Org.). Políticas e práticas da educação inclusiva. Campinas: Autores Associados, 2004. p. 69-91.

JANNUZZI, Gilberta. Escola e trabalho do considerado deficiente. SEMINARIO SOBREEDUCAÇÀO ESPECIAL: PROFISSIONALIZAÇÀO E DEFICIÂNCIA. 2., 1994, Campinas, SP. Anais... Campinas : UNICAMP, 1994.

JOSSO, Marie Christine. Experiências de Vida e Formação. São Paulo: Cortez, 2002.

KASSAR, Mônica de Carvalho Magalhães. Marcas da história social no discurso de um sujeito: Uma contribuição para a discussão a respeito da constituição social da pessoa com deficiência. Caderno Cedes, ano XX, no 50, abril/2000.

KIMMEL, D.C.; WEINER, I. La adolescencia: una transición del desarrollo. Barcelona: Ariel, 1998.

LIMA, R. P; MAIA, R.; DISTLER, S. D. Reflexão sobre um trabalho com famílias. Espaço, v.11, p. 37-39, 1999.

LOPES, J. R. Os caminhos da identidade nas ciências sociais e suas metamorfoses na Psicologia Social. Psicologia Social. v.14. n.1. p.7-27, 2002.

MANFEZOLLI, R. R. Olha eu já cresci: a infantilização de jovens e adultos com deficiência mental. 2004. Dissertação (Mestrado em Educação)-Universidade Metodista de Piracicaba, Programa de Pós-Graduação em Educação, Piracicaba, 2004. 
MYNAIO, Maria Cecília de Souza (organizadora), DESLANDES, Suely Ferreira. Pesquisa social: teoria, método e criatividade. Suely Ferreira Deslandes, Otávio Cruz Neto, Romeu Gomes, RJ: Vozes, 1994.

PÉREZ DE LARA FERRE, Nuria. Identidade, diferença e diversidade: manter viva a pergunta. In: LARROSA, Jorge; SKLIAR, Carlos. (Orgs.) Habitantes de Babel: políticas e poéticas da diferença. Belo Horizonte: Autêntica, 2001.

PIMENTEL, Susana Couto. (Con) viver (com) a Síndrome de Down em escola inclusiva: mediação pedagógica e formação de conceitos. (Tese de Doutorado), Salvador, 2007.

PIMENTEL, Susana Couto. A subjetivação da pessoa (d)eficiente no interior da escola: uma identidade a ser (des)construída. Educação em Revista, Marília, v.9, n.2, p.113-124, jul-dez, 2008.

SANTOS, José Vicente Tavares (org). Violência em Tempo de Globalização. José Vicente Tavares dos Santos. São Paulo, Hucitec, 1999.

SASSAKI, R. K. Inclusão: construindo uma sociedade para todos. 4. Ed. Rio de Janeiro: WVA, 1997.

SCHWARTZMAN, José Salomão. (Org.) Síndrome de Down. 2. Ed. São Paulo: Memnon: Mackenzie, 2003. 197.

SILVARES, E. F. M.; SHOEN-FERREIRA, T. H; AZNAR-FARIAS, M. A construção da identidade em adolescentes: um estudo exploratório. Estudos em Psicologia, Natal, v.8, n.1, p. 107-115, 2003.

SILVA, Luciene Maria da. Diferenças negada: O preconceito aos estudantes com deficiência visual. Salvador: EDUNEB, p. 69-71, 2009.

SMOLKA, A.L.B.O. O (im) prórpio e o im (pertinente) na apropriação das práticas sociais. Caderno Cedes, ano XX, no 50, abr/2000.

SOUZA. Elizeu Clementino de. O conhecimento de si: estágio e narrativas de formação de professores. Rio de Janeiro: DP\&A - Salvador, BA: UNEB, 2006, 184p.

THOMPSON, Paul. A voz do passado. História Oral. São Paulo: Paz e Terra. 2002.

VIEIRA, Ricardo. Histórias de vida e identidades. Professores e interculturalidade. Porto: Afrontamento, 1999.

VOIVODIC, Maria Antonieta M. A. Inclusão escolar de crianças de crianças com Síndrome de Down. 2. Ed. Petrópolis, RJ: Vozes, 2004.

VYGOTSKY, L.S. A formação social da mente. L.S. Vygotsky. São Paulo: Martins Fontes, 2001.

VYGOTSKY, L.S. Linguagem, desenvolvimento e aprendizagem. São Paulo: Editora da Universidaa de de São Paulo, 1988.

VYGOTSKY, L.S. Obras Completas V. Fundamentos de defectologia. Habana: Editorial. Pueblo y Educación, 1997.

WERTSCH, J. V. A necessidade da ação na pesquisa sociocultural. In: WERTSCH, J. V.; RIO, P.; ALVAREZ, A. Estudos Socioculturais da mente. Porto Alegre: Editora Artes Médicas Sul Ltda, 1998. p.5671. 
WUO, Andréa Soares. A construção social da Síndrome de Down. Caderno psicopedagogia. v.6 n.11 São Paulo, 2007.

\begin{tabular}{|c|c|}
\hline Informações do Artigo & Article Information \\
\hline Recebido em: 12/11/2020 & Received on: $12 / 11 / 2020$ \\
\hline Aceito em: 28/12/2020 & Accepted in: 28/12/2020 \\
\hline Publicado em: 31/12/2020 & Published on: $31 / 12 / 2020$ \\
\hline $\begin{array}{l}\text { Conflitos de Interesse: Os autores declaram não } \\
\text { haver quaisquer conflitos de interesse referente a } \\
\text { este artigo. }\end{array}$ & Conflict of Interest: No reported. \\
\hline Como citar este artigo & How to cite this article \\
\hline $\begin{array}{l}\text { Capistrano, L. L. M. (2020). O processo de } \\
\text { construção da identidade do adolescente com } \\
\text { síndrome de Down no atendimento } \\
\text { psicopedagógico. Revista Macambira, 4(2), } \\
\text { e042012. https://doi.org/10.35642/rm.v4i2.507 }\end{array}$ & $\begin{array}{l}\text { Capistrano, L. L. M. (2020). The process of } \\
\text { constructing the identity of adolescents with } \\
\text { Down syndrome in psychopedagogical care. } \\
\text { Revista Macambira, 4(2), e042012. } \\
\text { https://doi.org/10.35642/rm.v4i2.507 }\end{array}$ \\
\hline $\begin{array}{l}\text { Licença: } \\
\qquad \text { (c) (i) () (-) }\end{array}$ & (c) 9 ()이 \\
\hline $\begin{array}{l}\text { Este trabalho está licenciado sob uma Licença } \\
\text { Internacional Creative Commons Attribution- } \\
\text { NonCommercial-ShareAlike } 4.0 \text { International. }\end{array}$ & $\begin{array}{l}\text { This work is licensed under a Creative Commons } \\
\text { Attribution-NonCommercial-ShareAlike } \\
\text { International License. }\end{array}$ \\
\hline
\end{tabular}

